\title{
Epiglottic Abscess as a Complication of Foreign Body Ingestion
}

Yen-Ming Chen ${ }^{1}$, Chien-Chin Hsu ${ }^{1,2}$ and Kuo-Tai Chen ${ }^{1,3^{*}}$

${ }^{1}$ Emergency Department, Chi-Mei Medical Center, Tainan, Taiwan

${ }^{2}$ Department of Biotechnology, Southern Tainan University of Technology, Tainan, Taiwan

${ }^{3}$ Department of Emergency Medicine, Taipei Medical University, Taipei, Taiwan

*Corresponding author: Kuo-Tai Chen, Emergency Department, Chi-Mei Medical Center, 901 Chung-Hwa Road, Yung Kang, Tainan 710, Taiwan, Tel: 886-6-2812811 ext. 57196; Fax: 886-6-2816161; E-mail: 890502@mail.chimei.org.tw

Rec Date: May 27, 2016; Acc Date: October 05, 2016; Pub Date: October 11, 2016

Copyright: @ 2016 Chen YM, et al. This is an open-access article distributed under the terms of the Creative Commons Attribution License, which permits unrestricted use, distribution, and reproduction in any medium, provided the original author and source are credited.

\begin{abstract}
Foreign body-induced epiglottitis is rare and may not display typical manifestations of infectious epiglottitis. Besides, except for airway management and antibiotics treatment, the foreign body should be removed and accompanied complications, such as epiglottic abscess, also require adequate drainage. We reported on a patient admitted for epiglottitis and airway obstruction. Computed tomographic scan of the neck revealed an epiglottitis and a suspected retained epiglottic foreign body. The patient recovered completely after the removal of the foreign body and drainage of the abscess surgically. In the discussion, we describe the usefulness and limitations of laryngoscopic examination and computed tomographic scan of the neck for the evaluation of airway obstruction. If there is any suspicion of non-infectious causes of epiglottitis, or the response to treatment is inadequate, we suggest using varied diagnostic tools liberally to discover the accurate etiologies of epiglottitis.
\end{abstract}

Keywords: Epiglottitis; Epiglottic abscess; Foreign body; Computed tomographic scan; Surgery

\section{Background}

Epiglottitis is a potentially lethal disease because many of these patients require emergent airway management [1,2]. Infectious diseases constitute the majority of the etiologies of epiglottitis and these patients need antibiotic treatment and supportive care. However, there are a number of non-infectious causes that might alter the management of the patients [3-6]. We report on a patient who was admitted to our emergency department with epiglottitis induced airway obstruction. He underwent surgery for epiglottic abscess, which was caused by a retained fishbone.

\section{Case Presentation}

The 57-year-old male patient had a sore throat and dysphagia and visited the emergency department (ED). A day prior to his ED visit, he had had a dinner and felt a foreign body sensation in his throat but ignored it. Upon arrival, his vital signs were as follows: temperature: 36.1 , pulse rate: $73 / \mathrm{min}$, respiratory rate: $15 / \mathrm{min}$, and arterial pressures: 137/97 mmHg. Physical examination revealed a welldeveloped man without obvious respiratory distress. Inspection of his throat showed an erythematous throat, and auscultation of his neck and chest found no stridor or abnormal breathing sounds. Roentgenogram of the neck discovered epiglottic swelling (Figure 1) and acute epiglottitis was suspected. The laboratory test showed mild leucocytosis (white cell count: 11400/mm) and normal level of Creactive protein $(1.9 \mathrm{mg} / \mathrm{L})$.

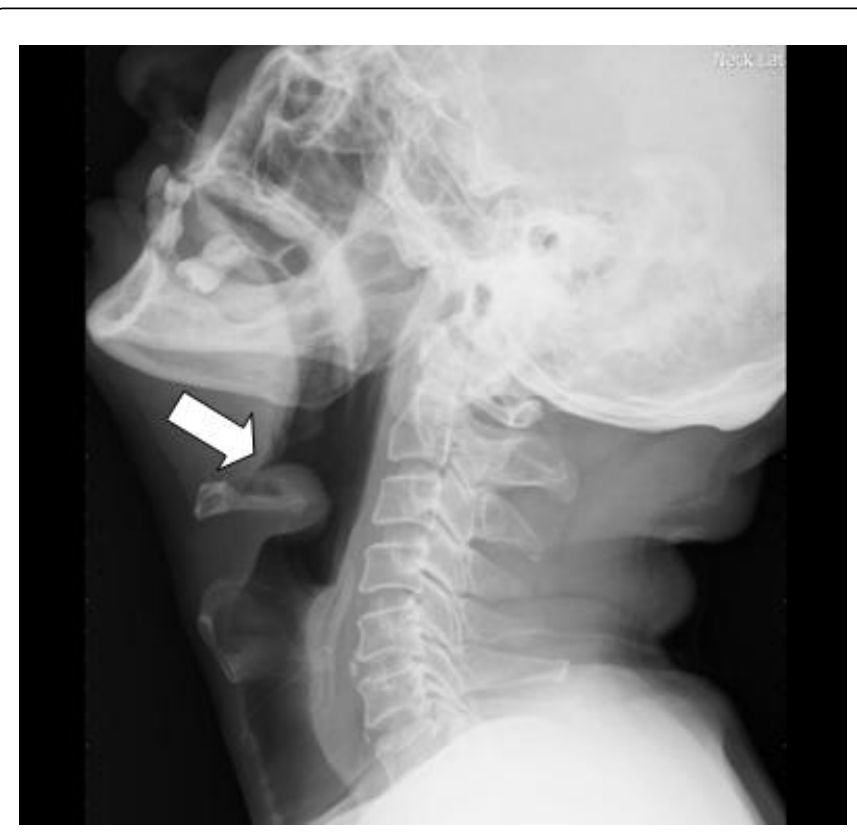

Figure 1: Roentgenogram of neck discovered a typical 'thumb sign' (arrow), which indicates the presence of epiglottic swelling.

According to the history of foreign body ingestion, we arranged a computed tomography (CT) scan of the neck, which demonstrated an epiglottic abscess and an impacted pin-like foreign body (Figure 2). The otolaryngologist-operated laryngoscopic examination revealed an erythematous, edematous epiglottis consistent with epiglottitis. The edema left a slit-like airway only. Therefore, the patient underwent a bronchoscopic-guided tracheal intubation for threatened airway obstruction. The otolaryngologist conducted a surgery to drain the 
abscess and a fishbone was removed from the patient's epiglottis. After five days of intravenous antibiotics and corticosteroid treatment, he was extubated and followed by a further three days' period of medical treatment. Finally the patient was discharged and 2 weeks later was seen in clinic with complete regression of inflammatory epiglottis.

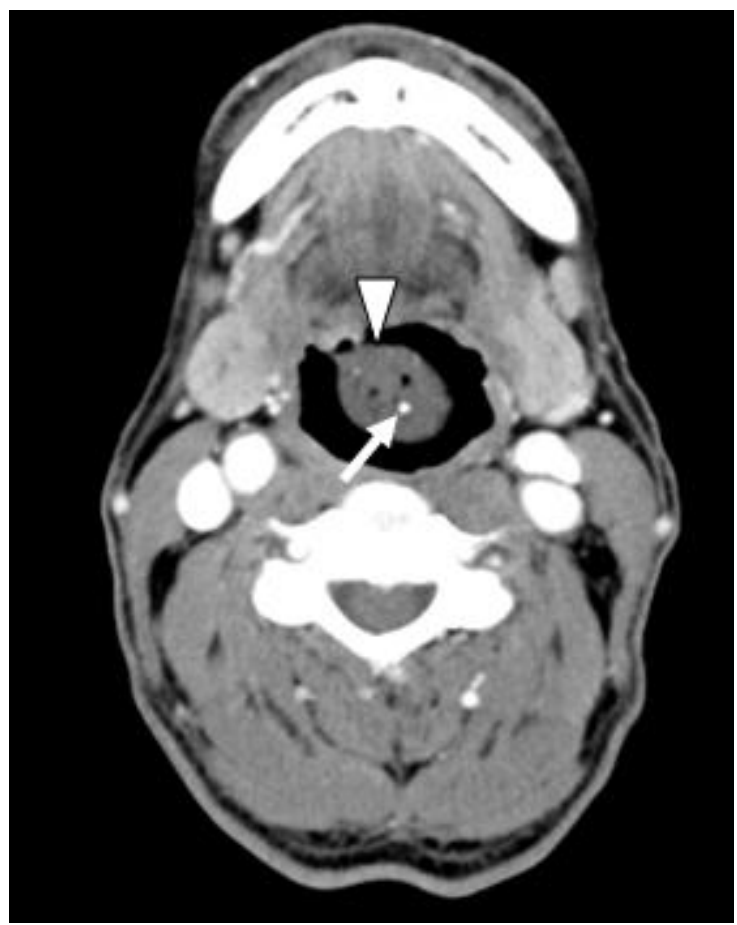

Figure 2: Computed tomographic scan of the neck. The arrowhead shows an enlarged epiglottis containing gas bubbles, which correspond to an epiglottic abscess. The white arrow points out a pin-like foreign body, which proved to be a fishbone bone in the ensuing surgery.

\section{Discussion}

Foreign body-induced airway obstruction has been reported in children, the elderly, and unconscious patients [3-7]. Unless the foreign body-related event is discovered, it is difficult to establish the actual etiology of the patient's airway obstruction. Additionally, many of these patients are incapable of describing their symptoms clearly. Furthermore, in the early stage of foreign body-induced epiglottitis, the patient may not present the typical manifestations of infectious epiglottitis, such as fever, neck tenderness or leukocytosis, which hampers the accurate diagnosis by the physician [6].
An otolaryngologist-operated laryngoscopy is the best examination for etiologies of upper airway obstruction and is also the diagnostic gold standard for epiglottitis [8]. However, in contemporary medical services, this examination is usually not available in every hospital around the clock.

A CT scan of the neck has been proposed as a practical diagnostic tool for epiglottitis. A CT provides a fair sensitivity, however, its specificity and positive predictive value are excellent [9]. In addition, CT demonstrates a great ability for the complications of epiglottitis, especially epiglottic abscess. A prospective study from South Korea showed that the incidence of epiglottic abscess can be up to $22 \%$ in patients with supraglottitis [10]. For patients who are unaware of foreign body ingestion, CT is also a useful images for retained foreign body. Accordingly, if an otolaryngologist-operated laryngoscopic examination is not available, we suggest patients with unknown causes of airway obstruction should undergo CT examination to delineate the etiologies. Once the epiglottic abscess or retained foreign body is discovered on CT images, surgical intervention is mandatory for a complete recovery from epiglottitis.

\section{References}

1. Mayo-Smith MF, Spindle JW, Donskey CJ, Yukawa M, Li RH, et al. (1995) Acute epiglottitis- An 18-year experience in Rhode Island. Chest 108: 1640-1647.

2. Lin PC, Liao YY, Hsu CC, Vong SC, Chen KT (2014) Comorbidities and complications influence the diagnosis and management of geriatric supraglottitis. Am J Emerg Med 32: 1334-1338.

3. Lai SH, Wong KS, Liao SL, Chou YH (2000) Non-infectious epiglottitisin children. Two case reports. Int J Pediatr Otorhinolaryngol 55: 57-60.

4. Mayo-Smith MF, Spindle J (1997) Thermal epiglottitis in adults: a new complication of illicit drug use. J Emerg Med 15: 483-485.

5. Tsai KK, Wang CH (2014) Acute epiglottitis following traditional Chinese Gua Sha therapy. CMAJ 186: E298.

6. Kavanagh KR, Batti JS (2008) Traumatic epiglottitis after foreign body ingestion. Int J Pediatr Otorhinolaryngol 72: 901-903.

7. Berzlanovich AM, Fazyny-Dorner B, Waldhoer T, Fasching P, Keil W (2005) Foreign body asphysic: a preventable cause of death in the elderly. Am J Prev Med 28: 65-69.

8. Al-Qudah M, Shetty S, Alomari M, Alqdah M (2010) Acute adult supraglottitis: current management and treatment. South Med J 103: 800-804.

9. Tan TH, Hsu CC, Liao YY, Chen KT (2014) Computed tomography scan as a diagnostic tool for supraglottitis in adults. Am J Emerg Med 32: 1278-1293.

10. Lee YC, Kim TH, Eun YG (2013) Routine computerised tomography in patients with acute supraglottitis for the diagnosis of epiglottic abscess: is it necessary A prospective multicentre study. Clin Otolaryngol 38: $142-147$. 